\title{
Safety Measures and First Aid Educational Program among Sports School Students and their Staff regarding Sports Injuries
}

\author{
Eman Fathy Mohamed Mahran ${ }^{1}$, Howyida Sadek Abd El-Hameed ${ }^{2}$, Amina Abd Elrazek \\ Mahmuod $^{3}$ and Hedya Fathy Mohy E-Deen ${ }^{4}$
}

(1) Nursing Teacher in Meet Kinana Nursing Institute for Males, (2) Professor of Community Health Nursing, Faculty of Nursing, Benha University and (3, 4) Assistant professor of Community Health Nursing, Faculty of Nursing, Benha University.

\begin{abstract}
Background: Injuries during sports and physical activities are a problem of public health especially for children and adolescents. This study aimed to evaluate the effect of safety measures and first aid educational program among sports school students and their staff regarding sports injuries. Research design: Quasi experimental design was used in carrying out this study. Setting: The study was conducted at Benha Secondary Sporting School. The sample: Convenient sample was used for the $1^{\text {st }}$ and $2^{\text {nd }}$ grade of secondary students (120) and all the staff (10). Three tools were used I): A structured interviewing questionnaire which consists of three parts to assess, 1: AStudents' demographic data. B-History of students`sports injuries. C-Staff - demographic data. DHistory of sports injuries for staff 2: Students' and staff' knowledge about sporting injuries. 3: Students' and staff' reported practices regarding application of first aid for sports injuries II): Observational check list to assess the environment of school. III): Observational check list to assess the practice of the staff and students regarding the application of injury safety measures during their practice. Results: $50 \%$ of students aged from 14 years and less than 16 years, and $50 \%$ of staff aged from 35 years to less than 45 years, $8.3 \%$ of the students had good knowledge regarding sports injury preprogram, however increased in post program to $65 \%$, while $50 \%$ of the staff had good knowledge regarding sports injury preprogram, and increased in post program to $80 \%$. Also $26.7 \%$ of students had satisfactory total practice scores preprogram, this percentage increased to $75 \%$ in post program. Moreover $60 \%$ of staff had satisfactory total practice scores preprogram, this percentage increased to $90 \%$ in post program Conclusion: There was a highly statistically significant positive correlation between students' and staff' total knowledge and total practices post educational program. Recommendations: Periodical safety measures and first aid training programs should be implemented for students and staff to improve their knowledge and practices regarding sports injuries.
\end{abstract}

Key Words: Sports injury, Safety measures, First aid, Educational program, Sports school

\section{Introduction:}

Sports injuries among school students are considered as one of the most serious health problems facing the world today because it can result in life long disability or even death: So basic life support becomes as important as preserving lives and minimizing the consequences of injuries until help is obtained. Deaths due to sports injuries account for $10 \%$ of the world's mortality (World Health Organization, 2016).

Sports injuries are most commonly caused 


\section{Safety Measures and First Aid Educational Program among Sports School}

\section{Students and their Staff regarding Sports Injuries}

by poor training technique in practice, inadequate equipment, overuse of a particular body part; structural abnormalities; weakness in muscles, tendons, ligaments; and unsafe exercising environments. The most common cause of injury is poor training. For example, muscles need 48 hours to recover after a workout (El magd, 2016).

Children and adolescents are more likely to suffer from sports injuries, their vulnerability is heightened by immature reflexes, and inability to recognize and evaluate risks. Injury rates are highest for athletes who participate in sports games with direct and recurrent contact, but the most serious injuries are associated with individual activities. Between one half and twothirds of childhood sports injuries occur during practice, or in the course of unorganized athletic activity (Abd El-Hafez, 2017).

A key component to sport's safety is ensuring that athletes adhere to proper guidelines and utilize proper protective equipment. Many sports such as hockey and football have regulations in place enforcing the use of safety equipment such as helmets, eye protection, mouth guards, and elbow and knee pads that are approved for every sport. Safety measures help in minimizing potential sport injuries (Mohamed et al., 2017).

According to The Occupational Safety and Health Administration (OSHA), (2019) : first aid is emergency care provided for injury or sudden illness before professional emergency medical treatment becomes available. In addition, first aid might mean the difference between life and death, between rapid recovery and a long hospitalization, or between a temporary and a permanent disability. First aid involves more than doing things for others.

The school nurse is a vital member of the school team that leads change to advance health and collaborates with school staff members, parents and community members to keep students safe at school and healthy to learn. The role of the school nurse encompasses both health and educational needs. In addition, school nurses may provide interventions for acute and chronic illness, injuries and emergencies, communicable diseases, obesity, substance use and abuse, mental health, dental disease, nutrition, and sexually transmitted infections. School nurses need to be physically present in schools to address these responsibilities appropriately (National Association of School Nurses, 2017).

Significance of the study:

In Egypt, injuries are a significant source of mortality and morbidity; they are the fifth leading cause of death. Injury is a common occurrence in many sports. Sports men are injured either by accident or intentionally by other players. School based student health surveys had been conduct in some (Mahran et al., 2016).

Accidents statistics show that a high percentage of all sports injuries occur during school sports. Depending on gender, age and the sport-related performance capabilities; school sports contributes to up to $51 \%$ of total injuries in youth. Even though most school sports injuries are minor and result in only temporary impairments. School sports injuries can lead to absence from school and therefore cause deficits in the transfer of knowledge. In this context, the undeniably positive sustainable effects of school sports on the physical and psychosocial development of the pupils must not be forgotten (Greier et al., 2018).

\section{Aim of the study:}

This study aimed to evaluate the effect of safety measures and first aid educational program among sports school students and their staff regarding sports injuries through:- 
1- Assessing knowledge of students and staff about sports injuries.

2- Assessing practices of students and school staff about safety measures and first aid for sports injuries.

3- Developing, implementing, and evaluating safety measures and first aid educational program for students and staff to improve their knowledge and practice.

\section{Research hypothesis}

After implementation of the safety measures and first aid educational program students' and staff's knowledge and practices about sporting injuries, first aid and safety measures will be improved.

\section{Subjects and method:}

Research design:

A quasi - experimental design was used in carry

\section{Setting:-}

The study was conducted at Benha Secondary Sporting School.

\section{Sampling:}

All students in the $1^{\text {st }}$ and $2^{\text {nd }}$ grade of secondary school were involved in the study and all the staff (10) in the above mentioned setting. The number of students in Benha Secondary Sporting School is 120 ranged for 30 students in every class for 4 classes for six months.

Tools for Data Collection: Three tools were used to collect data from students and staff involved in the study

\section{Tool (I): A structured interviewing} questionnaire: It was developed by the investigator, based on reviewing related literatures, and it was written in simple clear Arabic language, it is composed of three parts:

The first part: It was concerned with A-socio-demographic characteristics of students

B-Students' history of sports injuries

C-Socio-demographic characteristics of

D-Staff' history of sports injuries
The second part: It was concerned with students and staff knowledge about sports injuries.

\section{Scoring system:}

For each Knowledge question was calculated as follows: 2 points for correct and complete answer, 1 point for correct and incomplete answer, and zero for wrong or don't know answer. The total knowledge score was considered good if the score of the total knowledge $>75 \%$ ( $>18$ points), while considered average if it equals 50-75\% (12-18 points), and considered poor if it is $<50 \%$ ( $<12$ points).

The third part: was concerned with students and staff reported practices regarding application of first aid for sports injury through asking questions.

\section{ying out this study.}

The scoring system for students and staff' practices were calculated as follows 1 point for done, and zero for not done practicing.The total practices score was considered satisfactory if the score of the total practices is $>60 \%$ (> 29 points), while considered unsatisfactory if it is $\leq 60 \%$ ( $\leq 29$ points).

Tool (II): Observational checklist to assess the environment of the school

\section{Scoring system:}

The scoring system for school environment was calculated as follows 1 point for present, and zero for not present items. The school has sanitary environment if the score of the total present items is $>60 \%$ (>7) score), while considered unsanitary if it is $\leq 60 \%(\leq 7$ score .( Tool (III): It was concerned with students and staff' practices regarding safety measures for sports injuries،

A-Students practices regarding safety measures

B-Staff practices regarding safety measures

\section{Scoring system:}

The scoring system for students and staffpractices was calculated as follows 1 point for done, and zero for not done practicing. The 


\section{Safety Measures and First Aid Educational Program among Sports School}

Students and their Staff regarding Sports Injuries

total practices score was considered satisfactory if the score of the total practices is $>60 \%$, while considered unsatisfactory if it is $\leq 60 \%$.

\section{Content validity of the tools:}

The tools' validity was done by five of Nursing Faculty experts from the Community Health Nursing department who reviewed the tools for clarity, relevance, comprehensiveness, applicability and easiness for implementation and according to their opinion minor modification were carried out.

\section{Reliability of the tools:}

Reliability of the tool was tested by the researcher through testing the internal consistency of the tools

\section{Ethical considerations:}

All ethical issues were assured; approvals to conduct the study was obtained from the Dean of Faculty of Nursing and authorized personnel concerning title, objectives, tools; the study technique Oral consent has been obtained from students and staff before conducting the interview and before giving them a brief orientation to the purpose of the study. They were also reassured that all information gathered will be treated confidentially and used only for the purpose of the study. They were assured that they have the right to withdraw from the study at any time without giving any reasons.

\section{Pilot study:}

The pilot study carried out on $10 \%$ of the studied students (12) and staff (1). The pilot study was aimed to assess the tool clarity, applicability and time needed to fill each sheet as well as to identify any possible obstacles that may hinder the data collection. No modifications were done, so the pilot study sample was included to the total sample.

\section{Field work:}

Data were collected over a period of 6 months from the beginning of September 2019 to the end of February 2020. Approvals were obtained orally after the researcher introduced herself to the students and staff after explaining the purpose of the study. The study was carried out in the selected setting. The researcher visited Benha Secondary Sporting School, three days per week from 10.00 am to $1.00 \mathrm{pm}$ and sometimes from 9.00 am to 12.00 mid-day to collect data and cover the studied sample according to their educational schedule. The researcher implemented the program in 11 sessions in addition to 2 sessions for pre and posttest, during each session a group of 15 students or 5 staff was included: The researcher provided theoretical sessions through lectures, followed by discussion. Handouts, pictures, discussion, brain storming and role playing were used during the lecture to enhance acquisition of knowledge and to attract students and staff attention. The duration of the session was around 30-45 minutes according to the presented items. In the first session, the researcher introduced herself to participants and explained the aim of the study. Each session started by a summary about what was given during the previous session and the objectives of the new topics and ended by a summary of essential items discussed and performed. Finally the post test was done to evaluate the gained knowledge and practices immediately after the training program.

Safety measures and first aid educational program development included three phases:

Phase (I):- Program preparation: Based on pretest data obtained from interviewing questionnaire and observational checklist, as well as literature review, the program was developed by the researcher. It was implemented immediately after the pre- test .General objective of the program was to improve the students and staff' knowledge and 
practices regarding safety measures and first aid of sports injury.

\section{Phase (II): Implementation of the program:} The researcher implemented the program in 11 sessions in addition to 2 sessions for pre and posttest (total sessions $=13$ sessions). During the session a group of 15 students or 5 staff attended and the total hours of the sessions were 8 hours.

\section{Phase (III): Evaluation of the program:} Evaluation of the program was made by using the posttest questionnaire which exactly the same as the pretest in order to compare the change in students and staff' knowledge and practices. It was done immediately after implementation of the program

\section{Teaching methods:}

All students and staff received the same program content using the same teaching methods, there were:

-Modified lectures

-Discussion

-Brain storming

-Role play

\section{Teaching aid :}

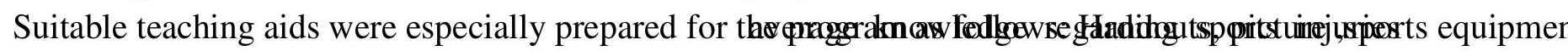

\section{Statistical design:}

All data collected were organized, tabulated and analyzed using the Statistical Package for Social Science (SPSS) version 20, which was applied to calculate frequencies and percentages as well as test statistical significance and associations by using chi-square test $\left(\mathrm{X}^{2}\right)$, and spearman correlation test $(r)$

Significance levels were considered as follows: Highly statistically significant $\mathrm{P}<0.001 * *$

Statistically significant $\mathrm{P}<0.05^{*}$

Not significant $\quad \mathrm{P}>0.05$

\section{Results:}

Table (1): Shows that, $50 \%$ of them aged 16 years to less than 20 years old and in the first secondary grade, $71.7 \%$ of them lived in the total knowledge and total reported practices post program $(\mathrm{P}>0.05)$. urban areas, 49, $2 \%$ of them had enough family income, all of them take 2 sport sessions per day and took 1 meal per day.

Table (2): Illustrates that; $50 \%$ of staff aged 35 years to less than 45 years old, $70 \%$ of them were highly qualified, $70 \%$ lived in the urban $\mathrm{m}$ areas, $90 \%$ were married, and $60 \%$ of them had enough income. Regarding to experience $50 \%$ of staff had 10 to less than $15 y e a r s, 70 \%$ of them had training course, while $71.4 \%$ had less than three training courses, and $100 \%$ of them had first aid course.

Figure (1): Illustrates that $8.3 \%$ of the students had good knowledge regarding sports injury, however percentage increased to $65 \%$ post program meanwhile, $61.7 \%$ of them had average knowledge regarding sports injuries compared to $30 \%$ post program and $30 \%$ of them had poor knowledge regarding sports imjadiefsedelectared to $5.0 \%$ post program.

Figure (2): Illustrates that $50 \%$ of the staff had good knowledge regarding sports injury, however percentage increased to $80 \%$ post program meanwhile, $40 \%$ of them had compared to $20 \%$ post program and $10 \%$ of them had poor knowledge regarding sports injuries which decreased to no one of them post program.

Figure (3): Reveals that $26.7 \%$ of students had satisfactory total practice scores preprogram, this percentage increased to $75 \%$ post program.

Figure (4): Reveals that $60 \%$ of students had satisfactory total practice scores preprogram, this percentage increased to $90 \%$ post program

Table (3): Shows that there was a highly statistically significant positive correlation between students' total knowledge and total reported practices post program $(\mathrm{P}>0.001)$.

Table (4): Shows that there was statistically significant positive correlation between staff' 
Table (1): Frequency distribution of studied students regarding socio demographic characteristic $(\mathbf{n}=120)$

\begin{tabular}{|l|l|l||}
\hline \multicolumn{1}{|c|}{ Students' socio-demographic characteristic } & \multicolumn{1}{l|}{ No. } & $\%$ \\
\hline \hline Age/years & 60 & 50.0 \\
\hline $14->16$ & 60 & 50.0 \\
\hline $16-20$ & 60 & 50.0 \\
\hline Class & 60 & 50.0 \\
\hline First & \multicolumn{2}{l|}{} \\
\hline Second & 34 & 28.3 \\
\hline Place of residence & 86 & 71.7 \\
\hline Rural & \multicolumn{2}{l|}{} \\
\hline Urban & 59 & 49.2 \\
\hline Family monthly income & 29 & 24.2 \\
\hline Enough & 32 & 26.6 \\
\hline Enough and save & 120 & 100.0 \\
\hline Not enough & 120 & 100.0 \\
\hline No of sport sessions per day (2 sessions) & 120 & 100.0 \\
\hline Receive a meal during the school day (Yes) & \\
\hline No of meals served (1) &
\end{tabular}


Table (2): Frequency distribution of studied staff regarding socio demographic characteristics $(\mathbf{n}=\mathbf{1 0})$.

\begin{tabular}{|c|c|c|}
\hline Staff' socio-demographic characteristic & No. & $\%$ \\
\hline \multicolumn{3}{|l|}{ Age } \\
\hline $25 \leq 35$ & 2 & 20.0 \\
\hline $35 \leq 45$ & 5 & 50.0 \\
\hline $45+$ & 3 & 30.0 \\
\hline \multicolumn{3}{|l|}{ Educational level } \\
\hline High qualification & 7 & 70.0 \\
\hline Postgraduate studies & 3 & 30.0 \\
\hline \multicolumn{3}{|l|}{ Place of residence } \\
\hline Rural & 3 & 30.0 \\
\hline Urban & 7 & 70.0 \\
\hline \multicolumn{3}{|l|}{ Social status } \\
\hline Single & 1 & 10.0 \\
\hline Married & 9 & 90.0 \\
\hline \multicolumn{3}{|l|}{ Monthly income } \\
\hline Enough & 6 & 60.0 \\
\hline Not enough & 4 & 40.0 \\
\hline \multicolumn{3}{|l|}{ Experience years } \\
\hline $5-$ & 2 & 20.0 \\
\hline $10-$ & 5 & 50.0 \\
\hline $15+$ & 3 & 30.0 \\
\hline \multicolumn{3}{|l|}{ Training courses } \\
\hline Yes & 7 & 70.0 \\
\hline No & 3 & 30.0 \\
\hline \multicolumn{3}{|l|}{ Number of training courses $(n=7)$} \\
\hline$<3$ & 5 & 71.4 \\
\hline $3-$ & 1 & 14.3 \\
\hline $5+$ & 1 & 14.3 \\
\hline \multicolumn{3}{|l|}{ Courses name $(\mathrm{n}=7) *$} \\
\hline First Aid & 7 & 100.0 \\
\hline Athletic Rehabilitation & 2 & 28.6 \\
\hline Flood rescue & 2 & 28.6 \\
\hline
\end{tabular}

*Responses are not mutually exclusive. 
Safety Measures and First Aid Educational Program among Sports School

Students and their Staff regarding Sports Injuries

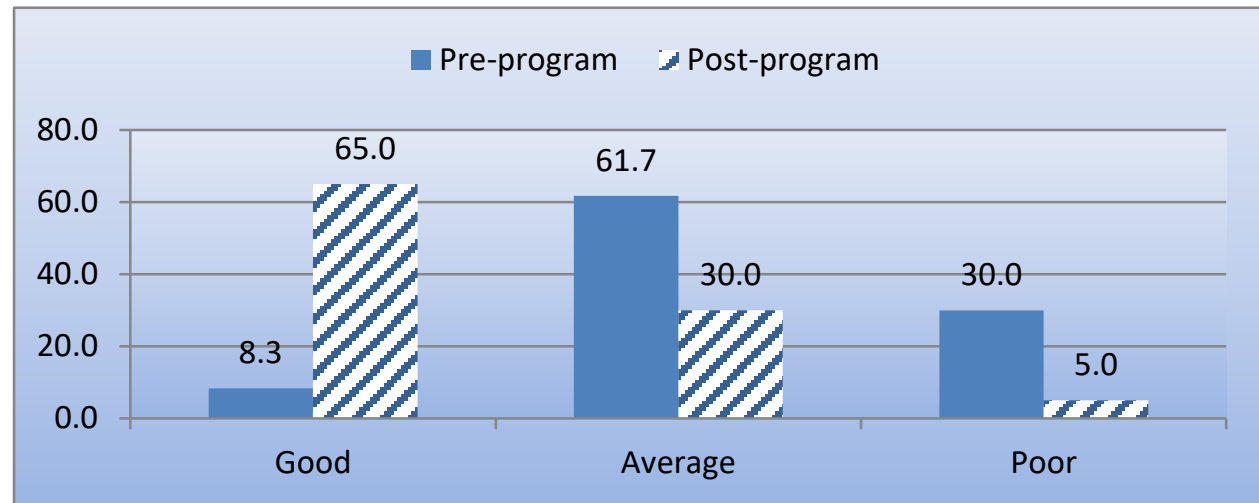

Figure (1): Percentage distribution of studied students regarding their total knowledge of sports injuries pre and post program $(n=120)$

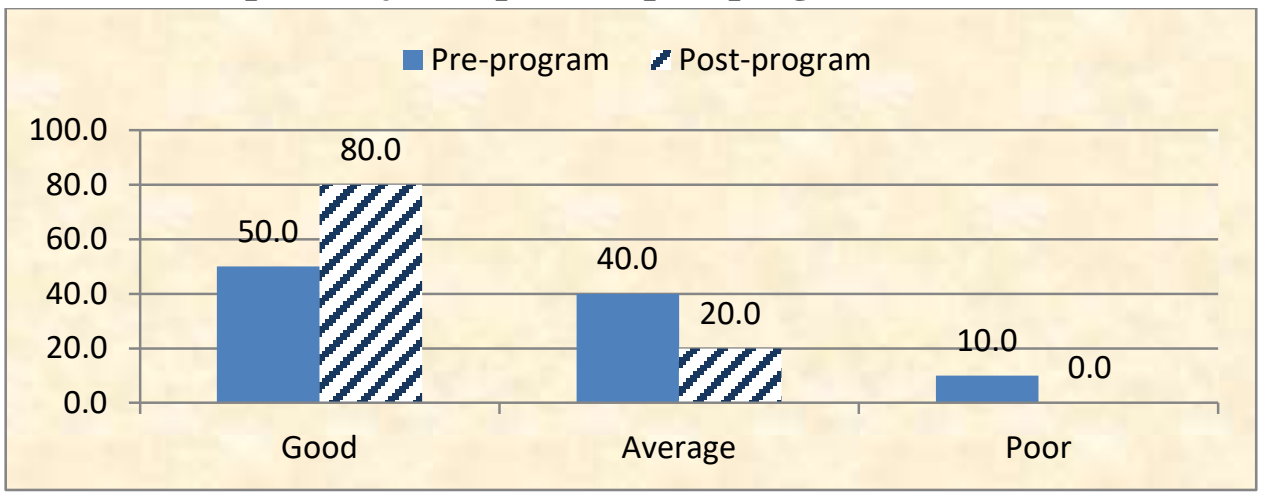

Figure (2): Percentage distribution of studied staff regarding their total knowledge of sports injuries pre and post program $(n=10)$

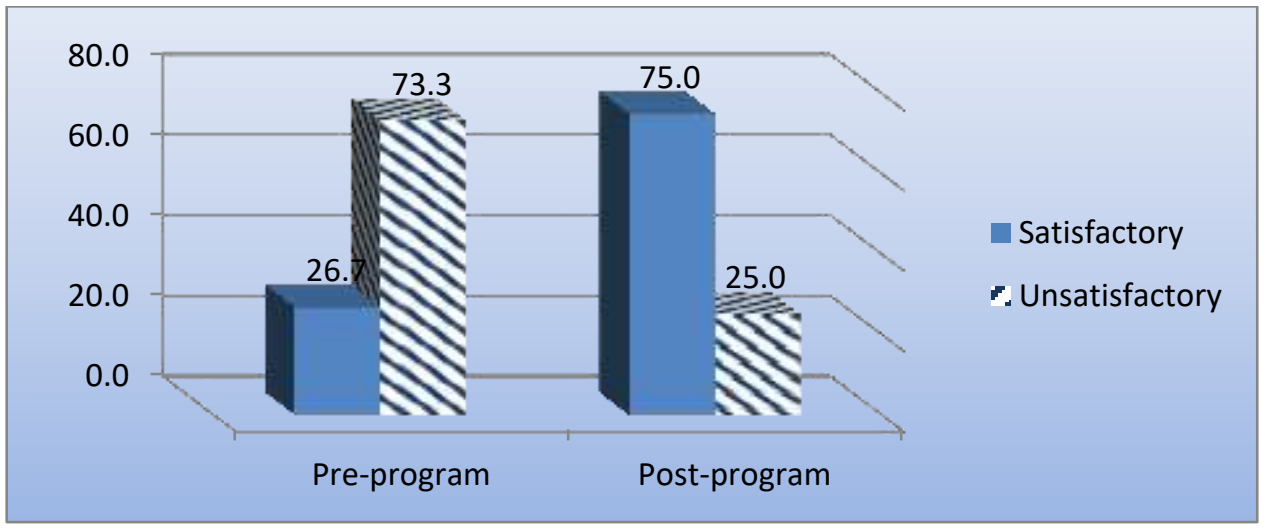

Figure (3): Percentage distribution of studied students concerning their total reported practices regarding sports injuries score pre and post program $(n=120)$

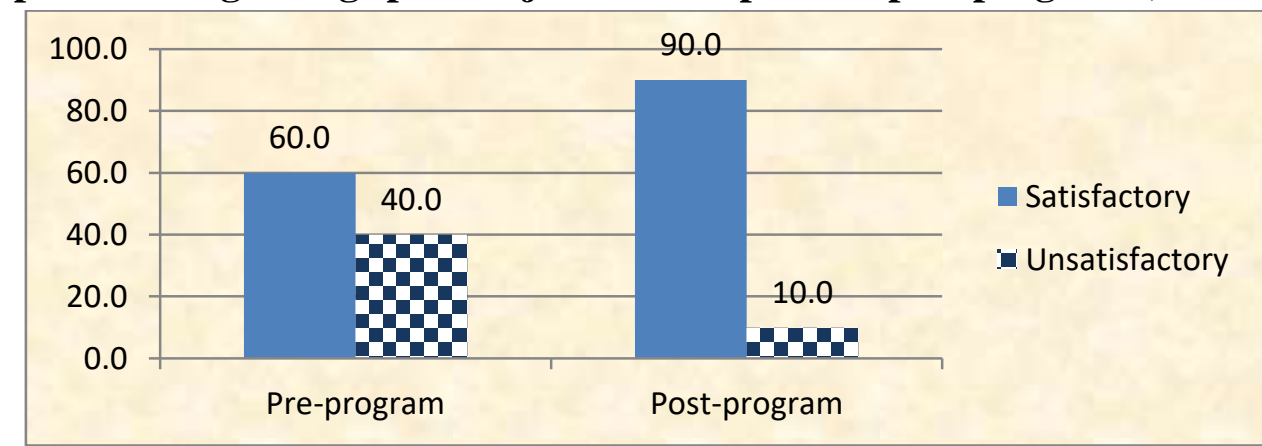

Figure (4): Percentage distribution of studied staff pertinent to their total reported practices level scores relevant to sports injuries pre and post program $(n=10)$ 
Table (3): Correlation between students' total knowledge score and total reported practices score regarding safety measures and first aid for sports injuries pre and post educational program

\begin{tabular}{|c|c|c|c|c|}
\hline \multirow{4}{*}{$\begin{array}{c}\text { Total reported } \\
\text { practice }\end{array}$} & \multicolumn{4}{|c|}{ Total knowledge } \\
\hline & \multicolumn{2}{|c|}{ Pre educational program } & \multicolumn{2}{|c|}{ Post educational program } \\
\hline & $\mathrm{r}$ & p-value & $\mathrm{r}$ & p-value \\
\hline & 0.137 & 0.135 & 0.73 & $0.000 * *$ \\
\hline
\end{tabular}

**Highly statistically significant $\mathbf{P}<0.001$

Table (4): Correlation between staff' total knowledge score and total reported practice score regarding safety measures and first aid for sports injuries pre and post educational program

\begin{tabular}{|c|c|c|c|c|}
\hline \multirow{4}{*}{ Total practices } & \multicolumn{4}{|c|}{ Total knowledge } \\
\cline { 2 - 5 } & Pre educational program & \multicolumn{2}{|c|}{ Post educational program } \\
\cline { 2 - 5 } & $\mathrm{r}$ & $\mathrm{p}$-value & $\mathrm{r}$ & $\mathrm{p}$-value \\
\cline { 2 - 5 } & 0.338 & 0.340 & 0.607 & $0.005^{*}$ \\
\cline { 2 - 5 } & &
\end{tabular}

*Statistically significant difference $\mathbf{P}<0.05$ Discussion:

According to socio demographic characteristic of the students, the finding of the present study showed that; half of students were 14 years to less than 16 years old and are in the first secondary grade, half of them were 16 years to less than 20 years old and are in the second secondary grade with the mean age of $16.75 \pm 1.32$. This finding was in agreement with Dasgupta et al., (2019), who reported that most of the students were 14 years of age $(58.09 \%)$. Also this finding was in congruence with Abd El-Hay et al., (2017), who reported that $40 \% \& 38.3 \%$ of the students aged from $15-16$ to 19 years respectively.

Regarding place of residence, the results of this study revealed that less than three quarters of students resided in urban areas. This finding was in contrast with Abd El-Hay et al., (2017), who noticed that more than half of students were from rural areas.
Also this finding disagreed with Ming et al., (2019), who reported that $82 \%$ of studied students were living in rural areas. This difference may be due to the fact that this sports school is the only one in Benha city Qaluobia governorate which is far from most rural areas.

In relation to sports sessions and meals, all of the students took 2 sport sessions per day and got one meal. Less than two thirds of them had another meal. This is due to the school system and the ministry of health, which assures that sports and nutrition are important factors for healthy body for students. This finding was similar to the study by Mohamed, (2017) who reported that all schools provide meals during the school day and more than three quarters of students indicating that the school provides them only with one meal per day.

As regards to the staff' socio demographic characteristics, the result of the 
present study showed that about half of staff aged 35 years to less than 45 years old with the mean age of $36.73 \pm 3.42$ half of staff had 10 to less than 15years of experience. This finding was in agreement with Noamesi et al., (2020), who reported $53 \%$ of technical staff was between 41-50 years of age and $73.3 \%$ of the technical staff had more than 2 years working experience.

In relation to marital status, the result of the present study showed that most of the staff was married and less than three quarters were urban residence. This finding was in agreement with El Magrabi et al., (2017), who reported that $88.0 \%$ of teachers were married and 83.3 were urban residents.

Regarding the educational level of the staff, the present study revealed that less than three quarters of them were highly qualified and had training course. This finding was in agreement with Siwon, (2018), who reported that the majority of the coaches completed college/ university or post graduate study, also reported that $25 \%$ to $50 \%$ of coaches attended training courses. While this finding was incongruent with Behairy and AlBatanony, (2016) who reported that $28.2 \%$ of studied group had university education and only $22 \%$ previously attended training courses about first aid and BLS.

In relation to students' total knowledge pre and post program, the present study illustrated that less than tens of the students had good knowledge regarding sports injury, however, this number increased in post program to two thirds. Meanwhile, less than two thirds of them had average knowledge regarding sports injury compared to one third in post program and one third of them had poor knowledge regarding sports injury preprogram decreased to less than one tenth in post program. This finding was in the same line with Chandrika, (2018), who reported that the majority of the children (59.4\%) had knowledge regarding the risk associated with the sports played. While this finding was incongruent with Mohamed, (2017), who reported that about half of students had poor knowledge regarding sports injury and $20.6 \%$ of them had good knowledge.

Regarding staff' total knowledge regarding sports injury pre and post program, the present study illustrated that half of the staff had good knowledge regarding sports injuries; however, the majority had knowledge regarding sports injuries in post program. Meanwhile, less than half of the staff had average knowledge regarding sports injury compared with less than one quarter in post program. One tenth of staff had poor knowledge regarding sports injury in preprogram and in post program this number decreased to no one. Similar findings were reported by Al kalash, (2019), who reported that there was a highly statistically significant difference in the participants' knowledge before and after application of the educational program ( $\mathrm{P}$ value < 0.001 ) as $69.3 \% \& 27.3 \%$ of them had very poor and poor knowledge respectively before conducting the educational session compared to $37 \% \& 23.7$ $\%$ of them had an excellent and very good knowledge regarding sports injury respectively after application of the educational program.

Regarding to students' total reported practice score pre and post program, the current study revealed that more than one quarter of student had satisfactory total reported practice scores preprogram. This percentage increased to three quarters post program. This finding was in agreement 
with Ali, (2017), who showed that there was highly statistically significant improvement in the level of total reported practice, immediately post program. The improvement in the level of total reported practice was from poor level $0.00 \%$ to 13.3 , $86.7 \%$ moderate and good levels respectively.

According to staff' total reported practice score pre and post program (Figure 8): the present study revealed that more than half of staff had satisfactory total reported practice scores preprogram. This percentage increased to "most of them" post program. This finding was consistent with Kamel, (2019), who clarified that there was improvement of the trainers practices from $57.8 \%$ preprogram to $84.3 \%$ post program.

In relation to the correlation between students' total knowledge and practice scores regarding safety measures and first aid of sports injuries pre and post educational program, the present study revealed that there was a highly statistically significant positive correlation between students' total knowledge and total reported practices post educational program $(\mathrm{P}>0.001)$. This finding might be due to improvement of the students' knowledge as a result of program implementation. . Also the correlation between knowledge and reported practice changed from negative to positive after the intervention indicating that the intervention did not only focus on delivering knowledge, but also on how to utilize this knowledge in practice.

As regards to correlation between staff' total knowledge and reported practice scores regarding safety measures and first aid of sports injuries pre and post educational program, the present study revealed that there was statistically significant positive correlation between staff' total knowledge and total reported practices post educational program ( $\mathrm{P}>0.05)$. This finding might be due to knowledge gained through program played important role for improving practices leading to high reported practice level. This finding was in agreement with Behairy and Al-Batanony, (2016), who mentioned that regarding level of good knowledge and correct practice of first aid and basic life support were significantly increased in the post intervention $\mathrm{P}<0.001$

Also this finding was supported by Masih et al., (2018), who reported that participants' knowledge and practices were improved after a teaching program (pretest knowledge mean score was $27.32 \pm 5.73$ and posttest knowledge mean score was $34.76 \pm$ 4.35 and pretest practices mean score was $14.52 \pm 2.39$ and posttest practice mean score was $18.52 \pm 2.63$. While this finding disagreed with Monica et al., (2018) who reported that coaches had good knowledge in managing the injuries but need periodic training for performing at emergencies.

\section{Conclusion}

The training program succeeded to improve students' and staff' knowledge and practice regarding safety measures and first aid for sports injury. Less than one tenth of the students had good knowledge regarding sports injury, however post program this figure increased to two thirds. Also half of the staff had good knowledge regarding sports injury, however, post program this figure increased to the majority. More than one quarter of students had satisfactory total reported practice scores preprogram, this percentage increased to three quarters post program. Moreover, less than three quarters of staff had satisfactory total safety measures practice scores preprogram, this percentage increased to "most" post program. Less than two thirds of staff had satisfactory total reported practice scores 
preprogram, this percentage increased to "most" post program. There was a highly statistically significant positive correlation between students' total knowledge and total reported practices post educational program. Also a statistically significant positive correlation between staff' total knowledge and total reported practices post educational program was found.

\section{Recommendations:}

- Continuous safety measures and first aid training program for students and staff to improve their knowledge and practices regarding sports injuries.

- Motivate students and staff to participate in safety measures and first aid training courses.

- All schools should be adequately prepared and equipped with proper instruments to protect and reduce sports injuries .

- Further studies need to be conducted focusing on prevention and management of sports injuries.

\section{References:}

Abd El-Hafez, S. (2017): Study of Safety Measures among Students and School Team in Sports and Military School. Master Degree. Community Health Nursing Department. Faculty of Nursing, Assiut University, Pp.2-3.

Abd El-Hay, S., Ibrahim, N., \& Hassan, L. (2017): Effect of Training Program Regarding First Aid and Basic Life Support on the Management of Educational Risk injuries among Students in Industrial Secondary Schools. Journal of Nursing and Health Science, 4(6). Pp 32-43.

Al kalash, S. (2019): Effect of Basic Life Support Training on Knowledge and Practice of Preparatory School Teachers in Sheben Elkom
City, Menoufia Governorate, Egypt, Egyptian Family Medicine Journal (EFMJ), 3(2), Pp. 1-18 Available at http://efmj.journals.ekb.eg/

Ali, S. (2017): Knowledge and Practice Towards Injury Safety Measures Among School Trainers and Students in Sports and Military Schools at Assiut Governorate. Assiut Scientific Nursing Journal, 5(12), PP. 20-32. https://doi.org/10.21608/asnj.2017.60415.

Behairy, A. \& Al-Batanony, M.(2016): Effectiveness of First-Aid and Basic Life Support Intervention Program on School Health Advisors. Journal of Health, Medicine and Nursing, 1(24), Pp.136-144. Available at https://core.ac.uk/download/pdf/234691746.pdf

Chandrika, $K$ (2018): Assessment of knowledge and attitude of children regarding the sports related traumatic injuries and its prevention using mouth guards. Master thesis, Ragas Dental College and Hospital, Chennai. Available at repository-tnmgru.ac.in/982.S/

Dasgupta, A., Bandyopadhyay, L. \&Das, M (2019): Effectiveness of Health Education in Terms of Knowledge Acquisition on First -Aid Measures among School Students of a Rural Area of West Bengal, Medico Research Chronicles, 1(2). Pp. 84-91.

El magd, M. (2016): Common Sports Injuries. International Journal of Physical Education, Sports and Health, 3(5). Pp. 3142-3148. https://doi.org/10.1016/B978-0-7216-0334-

6.50040-6

El magrabi, M., Aly, Sh. \& Khalaf, Sh. (2017): Impact of training program regarding first aid knowledge and practices among preparatory schools' teachers at Assiut City. Journal of Nursing Education and Practice, 7(12), P.89. Available at: https://doi.org/10.5430/jnep.v7n12p89

Kamel, A. (2019): Physical education safety precaution practices program in private preparatory school at Benha city. Doctoral 
thesis, Faculty of Physical Education, Benha University. PP. 115- 119..

Masih, S., Sharma, RK. And Kumar, A. (2018). Knowledge and practice of primary school teachers about first aid management of selected minor injuries among children. International journal of Medicine and Public Health, 4(4), PP.458-462. doi: 10.4103/22308598.144114.

Ming, H., GuoQing, U., Qiu, S. \& Xiang, E. (2019): Epidemiological Survey of the Prevalence of Non-fetal Injury among Children aged 5-14 Years in China, Biomedical and Environmental Sciences Journal, 25(4), Pp. 407412.

Mohamed, S. (2017): Study of Safety Measures among Students and School Team in Sports and Military School. Master Degree. Community Health Nursing Department. Faculty of Nursing, Assiut University, Pp.101-110.

Monica, M., Reddy, P., Anjum, S., Rao, Y., Prathibha, B. \& Sindhu, N. (2018): Cross sectional survey to assess the availability, accessibility in providing medical and dental services for traumatic injuries and knowledge of sports coaches, in sport academies of Hyderabad city, India. International Journal of Physical Education, Sports and Health, 5(5), Pp. 95-99. Available at https://www. kheljournal.com /archives/2018/vol5issue5/PartB/5-5-31-

483.pdf.accessed on 2/1/2021

National Association of School Nurses, (2017): Issue Brief: School Health Nursing Services Role in Health Care: Role of the School Nurse and definition of School Nursing. Silver Spring, MD: National Association of School Nurses; Available at: www.nasn.org/Default.aspx?tabid279

Noamesi, S., Quartey, J. \& Kwakye SK. (2020): Knowledge and Perception of the Role of Physiotherapy Among Members of Hockey Teams in Accra Ghana. Journal of Preventive and Rehabilitative Medicine, 2(1), Pp. 53-60. doi: 10.21617/jprm2020.219 $\begin{array}{lllr}\text { Occupational } & \text { Safety } & \text { and } & \text { Health } \\ \text { Administration } & \text { (OSHA), } & (2019): & \text { Best }\end{array}$

Practices Guide: Fundamentals of a Workplace First-Aid Program. Available at https://www.osha.gov/sites/default/files/publicat ions/OSHA3317first-aid.pdf

Patial , P., Thakare, G. \& Patial, S. (2017): Assessment of Knowledge, attitude and practices in coaches regarding musculoskeletal sport injuries and sports safety measures use among sports participants. Indian Journal of Clinical Anatomy and physiology. 4(1),Pp.63-67 Siwon, J. (2018): The Relation between High School Coaches' Beliefs about Sports Injury and Prevention Practice Readiness, doctoral thesis, philosophy department, community and family health college of public health university of south florida.

World Health Organization, (2016): Physical activity; fact sheet. 2016 .Available at http://www.who.int/ mediacentre/factsheets/fs385/en/. 


\section{برنامج تعليمي لوسائل الامان والإسعافات الأولية عن الإصابات الرياضية بين طلاب ومدربين المدرسة الرياضية الإية الاصنيا}

ايمان فتحي تحما مهران، هويدا صادق عبد الحميد، امينه عبد الرازق محمود، هليه فتحي محيالدين

إن المدارس الرياضية تجمع بين التربيه والتعليم وممارسه الرياضة وقد يعاني الطلاب من الإصابات الرياضية

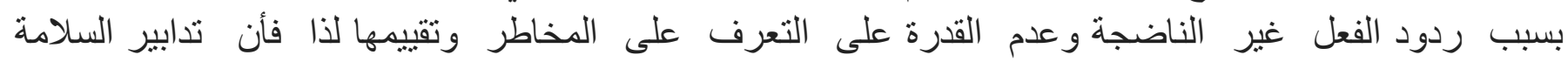

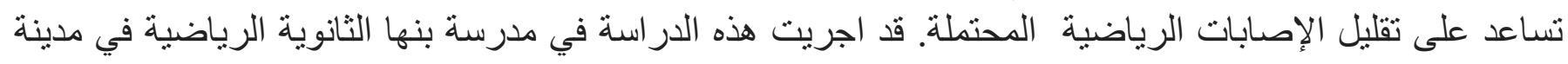

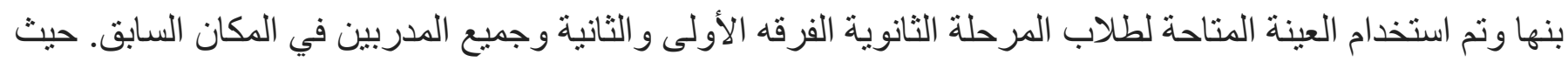

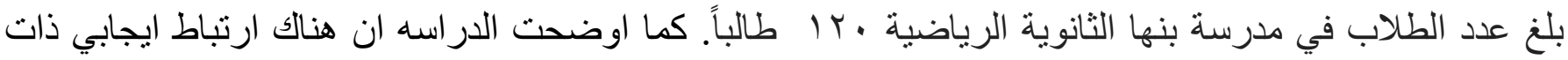

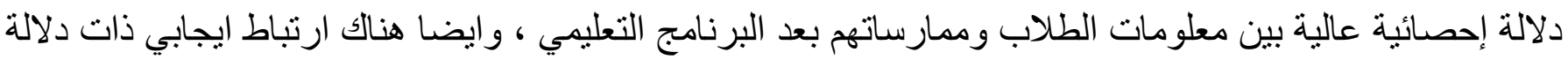

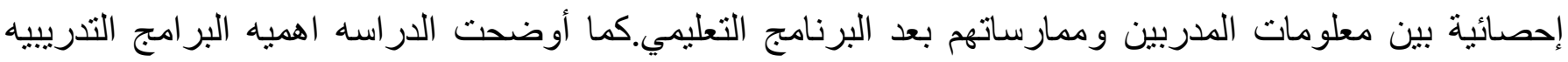

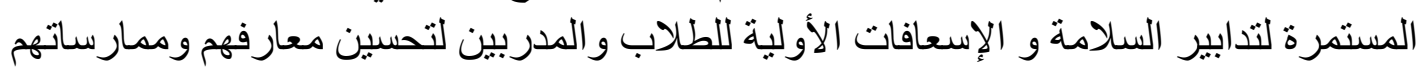

